\title{
Screening of Rice Genotypes for Drought Tolerance using Wax Petrolatum Layer Method
}

\section{R. Pushpam*, Vishnu Varthini Nachimuthu, S. Ashwathi, V. Amudhavalli, Haobijamjames Wat, S. Induram and S. Manonmani}

\author{
Department of Rice, CPBG, Tamilnadu Agricultural University, \\ Coimbatore - 641 003, Tamil Nadu, India \\ *Corresponding author
}

\section{A B S T R A C T}

\section{Keywords}

Rice genotype, Drought tolerance, Wax petrolatum.

\section{Article Info}

Accepted:

17 October 2017 Available Online: 10 December 2017
The development of a wax petrolatum layer method for screening the ability of rice (Oryza sativa L.) roots to overcome mechanical impedance is utilized in this study to identify drought tolerant lines. The ability of roots to penetrate compacted soils can be beneficial in terms of water uptake for avoiding drought stress. However breeding for root penetration is hindered by the lack of an efficient and reliable screening technique. Our objective in this study was to evaluate the use of a wax-petrolatum layer system as a reference to measure genotypic variation in root penetration ability of 28 rice (Oryza sativa L.) genotypes. The wax- petrolatum layers consisted of $60 \%$ wax and $40 \%$ petrolatum white, with a penetration resistance strength of $1.4 \mathrm{Mpa}$ at 27 degree Celsius. The waxpetrolatum layers were placed in plastic cups and served as a partial barrier for root penetration. Rice cultivars were sown in a randomized complete block design with two replications and grown in screen house. Drought stress was imposed at 25 days after sowing. Root sampling was done on $40^{\text {th }}$ day after sowing and several root morphological characters viz., root length, shoot length, root volume, basal root thickness, root fresh weight, shoot fresh weight, root dry weight, shoot dry weight, and root shoot dry weight ratio were measured. Based on the drought screening under wax petrolatum screening method, the genotypes viz., Norungan, Kallurandaikar, CB 09 516, CB 06 803, CB 08702, IR 83376-B-B-110-2, IRGC 12931, IRGC66774, Anna 4, IRGC 99696 and IR 72024 were identified as drought tolerant and the genotypes viz., IR 84882-B-120-CRD-4-1, IR 271513-IR-84887-B-154, IR 84895-B-127-CRA-5-5-1 and IR 1570-418-149-1 were found to be susceptible based on drought score index. PCV was marginally higher than the GCV for all traits. Heritability was high for all the traits studied i.e. root length, shoot length, root volume, basal root thickness, root fresh weight, root dry weight and shoot fresh weight except for shoot dry weight which has shown moderate heritability. Root length had high and positive correlation with shoot length, root volume and root dry weight. Root volume had significant and positive correlation with root thickness and root dry weight. Root thickness had positive correlation with root fresh weight and root dry weight. Hence the drought tolerant genotypes identified in this study can be effectively utilized as a donor for drought tolerance in drought breeding programmes. The drought screening method i.e., wax petrolatum screening method which focuses on root morphology is found to be reliable and could be used for drought screening at vegetative stage. 


\section{Introduction}

Rice (Oryza sativa L.) is the staple food for more than half of the world's population, especially those living in developing countries such as India, China, Pakistan, Bangladesh, Laos, Vietnam and Indonesia (Hadiarto and Tran, 2011). Rice together with wheat and maize provide $50 \%$ total calories consumed by world population (Maclean et al., 2002). Green Revolution has increased the rice production by 2.6 times since 1961 but focused mainly on irrigated ecosystems (Khush, 1999). But more than 40 million people depend directly on growing rice in the marginal agricultural uplands of South and South East Asia (Pandey, 2005). Poverty and food insecurity are major problems in upland agriculture, and stabilising rice production in these areas could be a key entry point for poverty reduction in the uplands and for achieving the Millennium Development Goals set out by the United Nations (Cairns et al., 2009).

Abiotic stress is the primary cause of crop loss worldwide, causing average yield losses of more than $50 \%$ for major crops (Bray et $a l ., 2000)$. Drought is one of the major abiotic stresses, affecting $20 \%$ of the total rice growing area in Asia (Pandey and Bhandari, 2008).

Achieving drought resistance in rice will be necessary for meeting the growing water shortage of the world, and it requires a deeper understanding of the mechanisms that could facilitate drought resistance (Serraj et al., 2011). Highly variable rainfall in the rice growing areas can introduce water stress at any stage of crop development. Drought has a major impact on plant growth and development, limiting crop production throughout the world. Plant adapt different strategies to combat drought depend on timing, severity and stage of growth.
Progress in developing high-yielding, drought-tolerant rice cultivars by conventional breeding has been slow, largely because of difficulties in precisely defining the target environment, complex interactions of drought tolerance with environments, and lack of appropriate screening methodology (Cooper et al., 1999; Wade et al., 1999). Due to the complexity of drought as a stress signal, interpreting drought tolerance mechanisms has remained a major challenge to plant biologists. Despite of the factors, yield improvements have been achieved in water limiting environments by selecting for secondary traits contributing to drought resistance in breeding programs. The effectiveness of selection for secondary traits to improve yield under water limiting environments has been successfully demonstrated for water use efficiency in wheat (Condon et al., 2004) and stay greenness in sorghum (Harris et al., 2007).

Several putative traits contributing to drought resistance in rice have been documented. Phenotypic selection for these putative traits involves complex labour intensive protocols and cost demanding experimental conditions. A practical approach for selection of drought resistant genotype is routinely based on the relative yield under stress to that under well watered condition (Ouk et al., 2006). Thus dissecting out the component traits of relevance and identifying the genomic regions influencing drought resistance mechanisms and grain yield will assist the breeders to know the genetic mechanism of this complex trait for development of varieties for drought prone environment.

Among the several traits contributing to enhance stress tolerance, root characters are considered to be a vital component of dehydration postponement mechanism since they contribute to regulation of plant growth and extraction of water and nutrients from 
deeper layers (Thanh et al., 1999). Several components of root morphology contributing to drought tolerance have been identified (Ekanayake et al., 1985a,b). A deep root system able to extract water at depth and respond to evaporative demand, provided there is water in the profile, is the most consensual of the traits contributing to drought avoidance at least in upland conditions (Yoshida and Hasegawa 1982; Nguyen et al., 1997; Price et al., 2002). In rice, significant genetic variation has been observed in various root traits (O'Toole and Bland, 1987; Lafitte et al., 2001). Considering these aspects, the present study was undertaken with 28 rice genotypes and were screened for drought tolerance using wax petrolatum layer screening method. From this study, drought tolerant and susceptible genotypes were identified which can be exploited as a potential donors in drought breeding programmes.

\section{Materials and Methods}

This present study was undertaken to screen the rice genotypes for drought resistance with emphasis on root traits. The experiment was conducted at Paddy Breeding Station (PBS), Centre for Plant Breeding and Genetics (CPBG), Tamil Nadu Agricultural University, Coimbatore during 2014. For screening drought tolerance, 28 rice genotypes were used. The rice genotypes were subjected to drought at vegetative stage at Department of Rice, Tamil Nadu Agricultural University, Coimbatore. A root penetration screening system was designed which used waxpetrolatum barriers as a substitute for compacted soil layers (Yu et al., 1995). This system was utilized to screen the root penetration ability of 28 rice genotypes.

The wax petrolatum layers used in this study consisted of $60 \%$ wax and $40 \%$ petrolatum by weight. This wax formulation had strength (mechanical impedance) of $1.4 \mathrm{Mpa}$ at 27 degree Celsius. The wax and petrolatum were combined in beakers in the appropriate weights to give a total weight of $50 \mathrm{~g}$. The mixture was then melted at 80 degree Celsius, mixed, poured into molds and allowed to solidify at room temperature. This experiment was conducted with a view to assessing the ability of test-genotypes to penetrate compacted soil layers formed during continued drought by means of a wax petrolatum layer system which simulated a partial barrier to root growth comparable to that caused by a compacted soil layer during such a drought (Yu et al., 1995).

Screening of rice genotype for root traits was carried out in a plastic cup. One hole was made in the bottom of the cup for aeration and water absorption at the bottom. Soil was filled to one third of the cup and then the prepared wax - petrolatum layer was poured into the cup with $1 \mathrm{~cm}$ thickness as a partial barrier to root growth. Above the layer, again soil was filled to about $3 \mathrm{~cm}$. Water was poured to moisten the soil. The seeds were sown and covered with red soil.

These plastic cups were placed in a tray, filled with water and it was maintained in green house. Two replications were carried out. The observations viz., Maximum root length, Shoot length, Root volume, Basal Root Thickness, Root fresh weight, Root Dry Weight, Shoot fresh weight, Shoot dry weight and Root Shoot Dry Weight Ratio were measured. The senescence of leaf, leaf rolling and leaf drying was scored using the scoring scale which was standardized for rice by IRRI (1996). The estimation of mean, variance and standard error were worked out by adopting the standard methods (Panse and Sukhatme, 1961). For each character PCV and GCV were computed based on the methods given by Burton (1952). Heritability $\left(h^{2}\right)$ in the broad sense was calculated according to Lush 
(1940) and Genetic advance was derived according to the method of Johnson et al., (1955) for each character under study.

\section{Results and Discussion}

This study was carried out to identify the rice genotypes resistant to drought and to study the effect of various root and shoot traits associated with drought resistance.

\section{Phenotypic characterization for Shoot and root traits}

The mean values are summarized trait wise in the Table 3. The results revealed that the entries IRGC 99696 and Norungan $(20.00 \mathrm{~cm}$ and $18.75 \mathrm{~cm})$ recorded higher root length than IR 1570-418-149-1 $(4.25 \mathrm{~cm})$ followed by the genotypes CB $08701(18.50 \mathrm{~cm})$, IRGC $66774(17.00 \mathrm{~cm})$. Root length ranged from $4.25 \mathrm{~cm}$ to $20.00 \mathrm{~cm}$ with a mean of $12.64 \mathrm{~cm}$. IRGC $72074(32.00 \mathrm{~cm})$ and IRGC $66774(28.75 \mathrm{~cm})$ recorded higher shoot length than IR 1570-418-149-1 (10.45 $\mathrm{cm})$. The genotypes exhibited variation in shoot length that varied from $10.45 \mathrm{~cm}$ to $32.00 \mathrm{~cm}$ with the average of $22.53 \mathrm{~cm}$.

Among the genotypes, IRGC $6087\left(1.75 \mathrm{~cm}^{3}\right)$ performed better than IR 1570-418-149-1 $\left(0.10 \mathrm{~cm}^{3}\right)$ for root volume. It showed the segregation range of $0.10 \mathrm{~cm}^{3}$ to $1.75 \mathrm{~cm}^{3}$. Correspondingly, the mean value is 0.768 $\mathrm{cm}^{3}$. IRGC 12931 and IRGC $66774(0.90$ $\mathrm{mm}$ ) had thicker roots than IR 78875-131-B1-4-1 $(0.10 \mathrm{~mm})$. The thickness of genotypes ranged from $0.10 \mathrm{~mm}$ to $0.90 \mathrm{~mm}$ with the mean value of $0.538 \mathrm{~mm}$. IR 2715-13-IR84887 -B-154 (0.663g) weighed more shoot fresh weight than IRGC $16261(0.023 \mathrm{~g})$. The shoot fresh weight ranged from $0.023 \mathrm{~g}$ to $0.663 \mathrm{~g}$ with the mean value of $0.226 \mathrm{~g}$.

The genotypes showed variability in shoot dry weight of which IRGC-6087 (0.215 g) weighed more than CB-09- 516 (0.019 g) The mean shoot dry weight is $0.093 \mathrm{~g}$. IRGC $6087(0.610 \mathrm{~g})$ had higher root fresh weight than IR 2715-13-IR-84887-B-154 (0.019g). The genotypes showed the range of 0.019 to 10.610 with the mean value of 0.199 . Anna 4 $(0.231 \mathrm{~g})$ recorded higher root dry weight than IR 1570-418-149-1 (0.008g) with the mean value of $0.083 \mathrm{~g}$.

\section{Drought score index}

Norungan, Kallurandaikar, IRGC 99696, TKM 9, Anna 4 (1.00) had less leaf senescence score when compared to IR 84882-B-120-CRD-41-1, IR 2715-13-IR84887-B-154, IR 84895-B-127-CRA-5-1-1, IRGC 16261 and IRGC 66774 (9.00) in stress condition. Among the genotypes a grand mean value of 5.43 with a range of 9.00 to 1.00 was recorded under stress. Norungan remained healthy without any leaf rolling when compared to IR 84882-B-120-CRD-41-1 (5.00). The genotypes recorded an average of 2.11 with a range of 0.00 to 5.00 under stress. Norungan remained healthy without any leaf drying when compared to IR 2715-13-IR-84887-B-154, IR 84895-B-127CRA-5-1-1 and IR1570-418-149-1 (9.00). The genotypes recorded an average of 4.04 with a range of 0.0 to 9.00 under stress (Table 2).

Leaf rolling found useful in assessing the levels of drought resistance in large scale screening of rice for drought tolerance (Chang et. al., 1974). Price and Courtois (1999) considered that triggering of leaf rolling was an indication of a plant suffering of moisture stress and suggested to select against its early manifestation. Leaf Senescence is an important trait with response to productivity under drought since the carbohydrate remobilization triggered by this process is vital in grain filling under drought. The drought tolerance was evident in the genotypes Norungan, Kallurandaikar, CB 09 
516, CB 06 803, CB 08702, IR 83376-B-B110-2, IRGC 12931, IRGC66774, Anna 4, IRGC 99696 and IR 72024 based on drought score index. The genotypes viz., IR 84882-B-
120-CRD-4-1, IR 2715-13-IR-84887-B-154, IR 84895-B-127-CRA-5-5-1 and IR 1570418-149-1 were found to be susceptible based on drought score index.

Table.1 Estimation of genetic parameters for different root and Shoot traits

\begin{tabular}{|l|l|l|c|}
\hline \multicolumn{1}{|c|}{ Characters } & GCV & PCV & Heritability \\
\hline Root Length $(\mathrm{cm})$ & 34.82 & 35.89 & 0.94 \\
\hline Shoot Length $(\mathrm{cm})$ & 17.37 & 21.95 & 0.63 \\
\hline Root Volume $(\mathrm{mm})$ & 60.62 & 65.80 & 0.85 \\
\hline Root Thickness $(\mathrm{mm})$ & 41.47 & 43.91 & 0.89 \\
\hline Shoot Fresh Weight $(\mathrm{g})$ & 65.51 & 67.89 & 0.93 \\
\hline Shoot Dry Weight $(\mathrm{g})$ & 36.52 & 58.93 & 0.38 \\
\hline Root Fresh Weight $(\mathrm{g})$ & 87.27 & 89.24 & 0.96 \\
\hline Root Dry Weight $(\mathrm{g})$ & 73.75 & 79.33 & 0.86 \\
\hline Leaf Senescence & 44.44 & 54.06 & 0.68 \\
\hline Leaf Rolling & 16.62 & 77.70 & -0.05 \\
\hline Leaf Drying & 66.22 & 71.77 & 0.85 \\
\hline
\end{tabular}

Table.2 Effects of characters on leaf drying

\begin{tabular}{|l|c|c|c|c|c|c|c|c|c|c|}
\hline & RL & SL & RV & RT & SFW & SDW & RFW & RDW & LSE & LR \\
\hline RL & 0.29 & -0.43 & -0.19 & 0.22 & 0.04 & 0.21 & -0.75 & 0.48 & -0.09 & -0.02 \\
\hline SL & 0.22 & -0.55 & -0.18 & 0.26 & 0.15 & 0.13 & -0.49 & 0.38 & 0.02 & -0.03 \\
\hline RV & 0.21 & -0.40 & -0.25 & 0.27 & 0.21 & 0.32 & -0.87 & 0.55 & 0.01 & -0.01 \\
\hline RT & 0.17 & -0.38 & -0.18 & 0.38 & 0.21 & 0.37 & -0.92 & 0.47 & 0.00 & -0.01 \\
\hline SFW & 0.02 & -0.18 & -0.11 & 0.16 & 0.48 & 0.38 & -0.63 & 0.24 & 0.13 & -0.02 \\
\hline SDW & 0.10 & -0.12 & -0.14 & 0.24 & 0.31 & 0.59 & -0.90 & 0.41 & 0.04 & -0.12 \\
\hline RFW & 0.16 & -0.21 & -0.17 & 0.26 & 0.23 & 0.40 & -1.31 & 0.61 & -0.05 & 0.03 \\
\hline RDW & 0.20 & -0.30 & -0.20 & 0.25 & 0.16 & 0.34 & -1.13 & 0.71 & -0.08 & 0.01 \\
\hline LSE & -0.07 & -0.03 & -0.01 & 0.00 & 0.18 & 0.07 & 0.18 & -0.15 & 0.35 & -0.08 \\
\hline LR & 0.07 & -0.20 & -0.03 & 0.03 & 0.15 & 0.90 & 0.48 & -0.08 & 0.36 & 0.08 \\
\hline
\end{tabular}


Table.3 Mean performance of rice genotypes for different drought tolerance traits

\begin{tabular}{|c|c|c|c|c|c|c|c|c|c|c|c|}
\hline Genotypes & $\begin{array}{c}\text { Root } \\
\text { length } \\
(\mathrm{cm})\end{array}$ & $\begin{array}{c}\text { Shoot } \\
\text { Length } \\
\text { (cm) }\end{array}$ & $\begin{array}{c}\text { Root } \\
\text { Volume } \\
\text { (cc) }\end{array}$ & $\begin{array}{c}\text { Root } \\
\text { thickness } \\
(\mathbf{m m})\end{array}$ & $\begin{array}{c}\text { Shoot } \\
\text { Fresh } \\
\text { Weight } \\
\text { (g) }\end{array}$ & $\begin{array}{c}\text { Shoot } \\
\text { dry } \\
\text { Weight } \\
\text { (g) }\end{array}$ & $\begin{array}{c}\text { Root } \\
\text { Fresh } \\
\text { Weight } \\
\text { (g) }\end{array}$ & $\begin{array}{c}\text { Root } \\
\text { dry } \\
\text { Weight } \\
\text { (g) }\end{array}$ & $\begin{array}{c}\text { Leaf } \\
\text { Senescence }\end{array}$ & $\begin{array}{c}\text { Leaf } \\
\text { Rolling }\end{array}$ & $\begin{array}{c}\text { Leaf } \\
\text { Drying }\end{array}$ \\
\hline Norungan & $18.75^{*}$ & 26.00 & 0.90 & 0.50 & 0.145 & 0.084 & 0.128 & 0.047 & 1 & 0 & 0 \\
\hline Kallurundaikar & $16.40 *$ & 22.95 & 0.60 & 0.45 & 0.132 & 0.062 & 0.098 & 0.035 & 1 & 1 & 3 \\
\hline CB-08-701 & $18.50 *$ & 26.25 & 1.50 & $0.70^{*}$ & $0.499 *$ & 0.119 & $0.390 *$ & $0.147 *$ & 5 & 3 & 5 \\
\hline CB - $09-516$ & 7.75 & 21.25 & 0.20 & 0.17 & 0.054 & 0.019 & 0.021 & 0.019 & 3 & 1 & 3 \\
\hline CB-07-701-279 & 5.50 & 22.50 & 0.15 & 0.40 & 0.172 & 0.126 & 0.052 & 0.040 & 7 & 1 & 3 \\
\hline CB $07-701-256$ & 14.50 & 21.35 & 0.40 & 0.56 & 0.125 & 0.064 & 0.040 & 0.031 & 5 & 3 & 7 \\
\hline CB-06-563 & 14.40 & 22.15 & 1.10 & $0.78 *$ & 0.215 & 0.124 & 0.222 & 0.075 & 7 & 3 & 3 \\
\hline CB 09512 & 9.70 & 22.5 & $1.20 *$ & 0.59 & 0.161 & 0.077 & 0.046 & 0.028 & 7 & 3 & 3 \\
\hline CB 06803 & 14.50 & 21.00 & 0.60 & 0.65 & 0.299 & 0.127 & $0.549 *$ & $0.162 *$ & 5 & 1 & 1 \\
\hline CB 08702 & 14.40 & 22.60 & 1.10 & $0.70 *$ & $0.350 *$ & 0.064 & $0.370 *$ & 0.088 & 5 & 1 & 3 \\
\hline $\begin{array}{c}\text { IR-83376-B-B- } \\
110-2\end{array}$ & $15.10 *$ & 23.40 & 0.90 & 0.50 & 0.191 & 0.079 & $0.318 *$ & $0.147 *$ & 5 & 1 & 5 \\
\hline $\begin{array}{l}\text { IR-84882-B-120- } \\
\text { CRD-4-1-1 }\end{array}$ & 14.75 & 26.50 & 0.50 & 0.40 & 0.120 & 0.093 & 0.081 & 0.039 & 9 & 5 & 7 \\
\hline $\begin{array}{c}\text { IR } 2715 \text {-13- IR- } \\
84887-B-154\end{array}$ & 5.35 & 24.35 & 0.40 & 0.41 & $0.663 *$ & 0.056 & 0.019 & 0.012 & 9 & 3 & 9 \\
\hline $\begin{array}{c}\text { IR-80021-B-86-3- } \\
\text { 4-CRD-1-2-1 }\end{array}$ & 14.50 & 22.00 & 0.50 & 0.50 & 0.146 & 0.063 & $0.306^{*}$ & 0.124 & 5 & 3 & 3 \\
\hline $\begin{array}{c}\text { IR-84895-B-127- } \\
\text { CRA-5-1-1 }\end{array}$ & 9.90 & 20.25 & 0.50 & 0.61 & 0.179 & 0.105 & 0.123 & 0.043 & 9 & 3 & 9 \\
\hline IR 1570-418-149-1 & 4.25 & 10.45 & 0.10 & 0.11 & $0.330 *$ & 0.159 & 0.020 & 0.008 & 7 & 5 & 9 \\
\hline $\begin{array}{l}\text { IR 78875-131-B-1- } \\
4-1\end{array}$ & 13.25 & 18.20 & 1.01 & 0.10 & 0.111 & 0.037 & 0.188 & 0.106 & 7 & 1 & 1 \\
\hline IR GC 99696 & $20.00 *$ & 26.00 & 1.10 & 0.70 & 0.162 & 0.101 & $0.328 *$ & 0.125 & 1 & 3 & 3 \\
\hline IRGC-16261 & 5.50 & 18.75 & 0.30 & 0.40 & 0.023 & 0.023 & 0.030 & 0.013 & 9 & 5 & 5 \\
\hline IRGC-72024 & $16.50 *$ & $32.00 *$ & $1.50 *$ & $0.70^{*}$ & 0.225 & 0.141 & 0.201 & $0.190 *$ & 3 & 3 & 3 \\
\hline
\end{tabular}




\begin{tabular}{|c|c|c|c|c|c|c|c|c|c|c|c|}
\hline IRGC-6087 & $16.25^{*}$ & 26.90 & $1.75^{*}$ & $0.89^{*}$ & $0.553^{*}$ & $0.215^{*}$ & $0.610^{*}$ & $0.168^{*}$ & 5 & 3 & 5 \\
\hline IRGC-12931 & 12.75 & 25.75 & 0.90 & $0.90^{*}$ & 0.284 & 0.112 & $0.472^{*}$ & $0.156^{*}$ & 3 & 1 & 3 \\
\hline IRGC 66774 & $17.00^{*}$ & $28.75^{*}$ & $1.30^{*}$ & $0.90^{*}$ & 0.286 & 0.089 & 0.172 & 0.113 & 3 & 1 & 3 \\
\hline $\begin{array}{c}\text { CR 2721-81-3-IR } \\
\text { 83380-B-B-124-1 }\end{array}$ & $15.50^{*}$ & 21.50 & 0.50 & 0.40 & 0.144 & 0.074 & 0.047 & 0.037 & 7 & 5 & 3 \\
\hline KMP 153 & 11.25 & 22.15 & 0.50 & 0.25 & 0.150 & 0.056 & 0.039 & 0.033 & 3 & 1 & 1 \\
\hline IR 20 & 9.25 & 17.20 & 0.60 & 0.60 & 0.290 & 0.123 & 0.270 & 0.058 & 5 & 3 & 5 \\
\hline TKM 9 & 12.25 & 22.50 & 0.15 & 0.41 & 0.125 & 0.097 & 0.065 & 0.050 & 1 & 3 & 5 \\
\hline Anna 4 & $16.25^{*}$ & 25.70 & $1.55^{*}$ & $0.88^{*}$ & 0.285 & 0.162 & $0.423^{*}$ & $0.231^{*}$ & 1 & 1 & 1 \\
\hline MEAN & $\mathbf{1 2 . 6 4}$ & $\mathbf{2 2 . 5 3}$ & $\mathbf{0 . 7 6 8}$ & $\mathbf{0 . 5 3 8}$ & $\mathbf{0 . 2 2 6}$ & $\mathbf{0 . 0 9 3}$ & $\mathbf{0 . 1 9 9}$ & $\mathbf{0 . 0 8 3}$ & $\mathbf{5 . 4 3}$ & $\mathbf{2 . 1 1}$ & $\mathbf{4 . 0 4}$ \\
\hline CD & $\mathbf{2 . 2 6}$ & $\mathbf{6 . 2 0}$ & $\mathbf{0 . 4 0}$ & $\mathbf{0 . 1 6}$ & $\mathbf{0 . 0 8}$ & $\mathbf{0 . 0 9}$ & $\mathbf{0 . 0 7}$ & $\mathbf{0 . 0 5}$ & $\mathbf{3 . 4 3}$ & $\mathbf{2 . 4 4}$ & $\mathbf{2 . 2 0}$ \\
\hline
\end{tabular}

Table.4 Correlation coefficient for different root and shoot traits

\begin{tabular}{|c|c|c|c|c|c|c|c|c|c|c|c|}
\hline Characters & $\begin{array}{l}\text { Root } \\
\text { Length } \\
(\mathbf{c m})\end{array}$ & $\begin{array}{c}\text { Shoot } \\
\text { Length } \\
\text { (cm) }\end{array}$ & $\begin{array}{c}\text { Root } \\
\text { Volume } \\
\text { (cc) }\end{array}$ & $\begin{array}{c}\text { Root } \\
\text { Thickness } \\
(\mathbf{m m})\end{array}$ & $\begin{array}{c}\text { Shoot } \\
\text { Fresh } \\
\text { Weight } \\
\text { (g) }\end{array}$ & $\begin{array}{l}\text { Shoot } \\
\text { Dry } \\
\text { Weight } \\
\text { (g) }\end{array}$ & $\begin{array}{c}\text { Root } \\
\text { Fresh } \\
\text { Weight } \\
\text { (g) }\end{array}$ & $\begin{array}{c}\text { Root } \\
\text { Dry } \\
\text { Weight } \\
\text { (g) }\end{array}$ & $\begin{array}{c}\text { Leaf } \\
\text { Senescence }\end{array}$ & $\begin{array}{c}\text { Leaf } \\
\text { Rolling }\end{array}$ & Leaf Drying \\
\hline Root Length & 1.00 & $0.68 *$ & $0.70^{*}$ & 0.57 & 0.10 & 0.29 & 0.56 & $0.66^{*}$ & -0.25 & 0.01 & -0.23 \\
\hline Shoot Length $(\mathrm{cm})$ & & 1.00 & 0.64 & 0.62 & 0.28 & 0.29 & 0.36 & 0.56 & 0.02 & 0.07 & -0.08 \\
\hline Root Volume(cc) & & & 1.00 & $0.70 *$ & 0.42 & 0.48 & 0.65 & $0.76^{*}$ & 0.02 & 0.02 & 0.02 \\
\hline $\begin{array}{l}\text { Root } \\
\text { Thickness(mm) }\end{array}$ & & & & 1.00 & 0.41 & 0.54 & $0.69 *$ & $0.67 *$ & 0.01 & 0.07 & 0.11 \\
\hline $\begin{array}{l}\text { Shoot Fresh } \\
\text { Weight(g) }\end{array}$ & & & & & 1.00 & 0.53 & 0.47 & 0.33 & 0.31 & 0.05 & 0.46 \\
\hline Shoot Dry Weight(g) & & & & & & 1.00 & 0.57 & 0.54 & 0.06 & 0.27 & 0.29 \\
\hline $\begin{array}{l}\text { Root Fresh } \\
\text { Weight(g) }\end{array}$ & & & & & & & 1.00 & $0.85 * *$ & -0.13 & -0.08 & -0.04 \\
\hline Root Dry Weight(g) & & & & & & & & 1.00 & -0.20 & -0.04 & -0.05 \\
\hline Leaf Senescence & & & & & & & & & 1.00 & 0.31 & 0.43 \\
\hline Leaf Rolling & & & & & & & & & & 1.00 & 0.56 \\
\hline Leaf Drying & & & & & & & & & & & 1.00 \\
\hline
\end{tabular}

*Significant at 5 per cent level, **significant at 1 per cent level 


\section{Genetic parameters}

The ANOVA for the various component traits of drought resistance was estimated in the rice genotypes under stress conditions. The genetic parameters such as phenotypic coefficient of variation (PCV), genotypic coefficient of variation (GCV) and the broad sense heritability were computed and presented in the Table 1. Among the rice genotypes studied, highly significant genotypic differences were observed for most of the traits under stress condition. PCV was much higher than the GCV for all traits under stress. The trait root fresh weight, root dry weight, shoot fresh weight and root volume exhibited high PCV (89.24, 79.33, 67.89 and 65.80) and GCV (87.27, 73.75, 65.51 and $60.62)$ respectively under stress condition. Based on the classification given by Sivasubramian and Madhavamenon (1973), PCV and GCV were high for all the root traits indicating that the variability observed was high. Heritability specifies the proportion of the total variability that is due to genetic causes. It is a good index of transmission of characters from parents to their offspring (Falconer, 1960). Information on heritability of root traits are still very limited (Gowda et al., 2011). The present investigation has recorded high heritability for the traits studied except for shoot dry weight.

Broad sense heritability $\left(h^{2}\right)$ was estimated for different traits under stress condition. The traits namely root fresh weight, root length, shoot fresh weight, root thickness, root dry weight, root volume, leaf drying, leaf senescence and shoot length had high heritability $\left(\mathrm{h}^{2}\right)$ values of 96.00, 94.00, 93.00, 89.00, 86.00, 85.00, $85.00,68.00$ and 63.00 respectively under stress condition.

The correlation coefficient among various component traits related to drought tolerance with the leaf drying under stress condition were estimated and presented in Table 4 . The correlation study showed root length had significant and positive correlation with shoot length (0.68), root volume (0.70) and root dry weight (0.66) under drought stress. Root volume exhibited significant and positive correlation with root thickness (0.70) and root dry weight (0.76). Root thickness showed significant and positive correlation with root fresh weight (0.69) and root dry weight (0.67). Root fresh weight exhibited highly significant and positive correlation with root dry weight (0.85).

Correlation implies a cause and effect relationship between variables. In rice, it is used to find the effect of various traits on yield (John F Kennedy and Rangasamy, 1998). It is an index of degree of relationship between two continuous variables. Correlating genetic information with physiomorphological traits related to drought resistance will allow the development of drought resistant rice cultivars through indirect selection.

All the root traits had highly significant positive correlation with each other. Total root length is strongly related to drought tolerance in rice under drought condition (Ingram et al., 1994). Thick roots might have greater capacity for water uptake from deeper soil layers (Yambao et al., 1992). Thick roots are also hypothesized to confer drought tolerance because root branching is related to root thickness (Fitter, 1991). Thick roots persist longer and produce more and larger root branches, thereby increasing the root length density and water uptake capacity (Ingram et al., 1994). In this study, root length had high and positive correlation with shoot length, root volume and root dry weight. Root volume had significant and positive correlation with root thickness and root dry weight. Root thickness had positive correlation with root fresh weight and root dry 
weight. Similar results were reported by Toorchi et al., (2002) and Vishnu varthini et al., (2011). From this study, the drought tolerant genotypes Norungan, Kallurandaikar, CB 09 516, CB 06 803, CB 08702, IR 83376B-B-110-2, IRGC 12931, IRGC66774, Anna 4, IRGC 99696 and IR 72024 identified can be effectively utilized as a donor for developing drought tolerant lines. Further, the drought screening method i.e., wax petrolatum screening method is found to be reliable and could be used for drought screening at vegetative stage.

\section{References}

Ali, M.L.M., Pathan J Zhang. G. Bai. S. Sarkarung and H.T. Nguyen 2000. Mapping QTL for root traits in a recombinant inbred population from two indica ecotypes in rice. Theor. Appl. Genet., 101: 756-766.

Amenta-Sota, J., T.T. Chang, Loresto, G.C and O'Toole, J. 1983. Genetic analysis of Root characteristics in rice. SABRAO J. 15: 103-118.

Arrandeau, M.A. 1989. Breeding strategies for drought resistance. In: Drought Resistance in Cereals (Ed) E.W.G. Baker. CAB International, UK. Pp. 107116

Asch, F., M. dingkuhn, A. Sow and A. Audebert. 2004. Drought-induced changes in Rooting patterns and assimilate partitioning between root and shoot in upland Rice. Field crops Res. 93: 223-236.

Atlin, G.N., R. Venuprasad, J. Bernier, D. Zhao, P. Virk, and A. Kumar. 2008. Rice germplasm development for drought-prone environments: progress made in breeding and genetic analysis at the International Rice Research Institute (IRRI). In: Serraj, R., Bennett, J., Hardy, B. (Eds.), Drought Frontiers in Rice: Crop Improvement for Increased
Rainfed Production. International Rice Research Institute/World Scientific, Los Banos, Philippines/Singapore. Pp. 3559.

Babu, R.C., H.E. Shashidhar, J.M. Lilley, J.D. Ray, S. Sadasivam and S. Sarkarung et $a l ., 2001$. Variation in root penetration ability, osmotic adjustment and dehydration tolerance among accessions of rice adapted to rainfed lowland and upland ecosystems. Plant Breed. 120: 233-238.

BasuRaychaudhuri, N.C. and D.K. Das Gupta. 1981. Morphological characters of rice associated with drought tolerance in uplands. Oryza, 18: 150152.

Blum, A. 2002. Drought tolerance - is it a complextrait. In: Field Screening for drought tolerance in crop plants with emphasis of rice. (Eds.). N.P. Saxeena and J.O' Toole pp. 17-22. ICRISAT, Patancheru, India.

Chang, T.T., G. Loresto and P.O. Tagum. 1974. Screening rice germplasm for drought resistance. SABRAO Journal, 6: 9-16.

Chang, T.T., G.C. Loresto, J.C. O'Toole and J.L. Armenta-Soto. 1982. Strategy and methodology of breeding rice for drought prone areas. In: Drought Resistance in Crops, with Emphasis on Rice. International Rice Research Institute, Manila, Philippines.

Clark, L.J., A.H. Price, K.A. Steele and W.R. Whalley. 2008. Evidence from nearisogenic lines that root penetration increases with root diameter and bending stiffness in rice. Funct. Plant Biol. 35: 1163-1171.

Clark, L.J., S.L. Aphalé and P.B. Barraclough. 2000. Screening the ability of rice roots to overcome the mechanical impedance of wax layers: importance of test conditions and measurement criteria. Plant Soil 219: 
187-196.

Ekanayake, I.J., J.C. O’Toole, T.M. Masajo and D.P. Garrity. 1985a. Root pulling resistance in rice: inheritance and association with drought tolerance. Euphytica, 34: 905-913.

Ekanayake, I.J., J.C. O’Toole, D.P. Garrity and T.M. Masajo. 1985b. Inheritance of root characters and their relations to drought resistance in rice. Crop Sci., 25: 927-933.

Fukai S and M Cooper. 1995. Development of drought resistant cultivars using physiomorphological traits in rice. Field Crops Res., 40: 67-86.

Fukai, S., G. Pantuwan, B. Jongdee and M. Cooper. 1999. Screening for drought resistance in rainfed lowland rice. Field Crops Res, 64: 61-74.

Garrity, D.P. and J.C. O'Toole. 1994. Screening rice for drought resistance at the reproductive stage. Field Crops Res, (in press).

Hoque MM and T Kobata. 1998. Growth responses of drought resistant rice cultivars to soil compaction under irrigated and succeeding non-irrigated conditions during the vegetative stage. Plant Prod Sci., 1: 183-190.

Horii, H., K. Nemoto, N. Miyamoto and J.
Harada. 2006. Quantitative trait loci for adventitious and lateral roots in rice. Plant Breed. 125: 198-200.

IRRI. 1996. Standard Evolution System for Rice. fourth edn. International Rice Research Institute, Manila, The Philippines.

Kamoshita, A., R.C. Babu, N.M. Boopathi and S. Fukai S. 2008. Phenotypic and genotypic analysis of drought-resistance traits for development of rice cultivars adapted to rainfed environments. Field Crops Res., 109: 1-23.

Yoshida, S. and S. Hasegawa. 1982. The rice root system: its development and function. In: Drought resistance in crops with emphasis on rice. (Ed) J.C. O'Toole. Los Baños, Laguna: IRRI. pp 97-114.

Yu, L., J. D. Ray, J.C. O'Toole and H.T. Nguyen. 1995. Use of wax-petroleum layers for screening rice root penetration. Crop Sci., 35: 684-687.

Zheng, H., R. Babu, M. Pathan, L. Ali, N. Huang and B. Courtois et al., 2000. Quantitative trait loci for rootpenetration ability and root thickness in rice: comparison of genetic backgrounds. Genome43:53-61.

\section{How to cite this article:}

Pushpam, R., Vishnu Varthini Nachimuthu, S. Ashwathi, V. Amudhavalli, Haobijamjames Wat, S. Induram and Manonmani, S. 2017. Screening of Rice Genotypes for Drought Tolerance using Wax Petrolatum Layer Method. Int.J.Curr.Microbiol.App.Sci. 6(12): 2397-2406. doi: https://doi.org/10.20546/ijcmas.2017.612.277 